\title{
INOVAÇÕES TECNOLÓGICAS BASEADAS NA ECONOMIA COLABORATIVA OU ECONOMIA COMPARTILHADA E A LEGISLAÇÃO BRASILEIRA: O CASO UBER
}

\author{
Jamili El Akchar Salman ${ }^{1}$ \\ Jorge Shiguemitsu Fujita ${ }^{2}$
}

\section{RESUMO}

Este artigo aborda aspectos jurídicos das inovações tecnológicas baseadas em economia compartilhada, que têm rompido com modelos de negócio tradicionais, democratizado o acesso aos bens e serviços e fomentado a economia. Porém, tem gerado diversos conflitos sociais e desafios ao Direito, como é o caso da UBER, plataforma tecnológica que aproxima prestadores de serviços de transporte aos demandantes, usuários (peer-to-peer). Taxistas alegam inconstitucionalidade e ilegalidade do serviço, apesar de nossa Constituição defender a livre iniciativa, a livre concorrência e a busca do pleno emprego. A pacificação social somente foi alcançada através da regulamentação do transporte remunerado privado individual de passageiros.

Palavras-chave: Sociedade da Informação; Economia Compartilhada; Peer-to-peer; UBER; Lei 13.640/2018.

\section{TECHNOLOGICAL INNOVATIONS BASED ON THE SHARED ECONOMY AND THE BRAZILIAN LEGISLATION: THE UBER CASE}

\begin{abstract}
This article discusses legal aspects of technological innovations based on shared economy, which have broken with traditional business models, democratized access to goods and services and fostered the economy. However, it has generated several social conflicts and challenges to the Law, as is the case of UBER, a technology platform that brings together transport service providers to users (peer-to-peer). Taxi drivers allege unconstitutionality and illegality of the service, although our Constitution defends free initiative, free competition and the pursuit of full employment. Social pacification was only achieved through the regulation of individual private passenger transportation.
\end{abstract}

Keywords: Information Society; Shared Economy; Peer-to-peer; UBER; Law 13.640/2018.

\footnotetext{
${ }^{1}$ Mestranda bolsista pela CAPES em Direito da Sociedade da Informação pelo Programa de Mestrado em Direito da Sociedade da Informação do Centro Universitário das Faculdades Metropolitanas Unidas - FMU de São Paulo. MBA em Gestão Estratégica e Econômica de negócios e projetos pela Fundação Getúlio Vargas de São Paulo. Graduada em Sistemas de Informação pela Universidade São Judas Tadeu. Advogada sóciafundadora do Escritório Akchar \& Ruiz assessoria e consultoria jurídica. São Paulo - SP, Brasil.

${ }^{2}$ Doutor em Direito Civil pela Faculdade de Direito da Universidade de São Paulo; Bacharel em Direito pela Faculdade de Direito da Universidade de São Paulo. No magistério é: a) Professor Emérito e Titular de Direito Civil na Graduação e no Mestrado do Centro Universitário das Faculdades Metropolitanas Unidas - FMU (São Paulo - SP); b) Auxiliar Doutor do Curso de Pós-Graduação da Faculdade de Direito da Universidade de São Paulo - USP; c) Professor contratado do Curso de Pós-Graduação da Escola Superior de Advocacia da Ordem dos Advogados do Brasil, Seção de São Paulo - SP; d) Professor visitante do Curso de Pós-Graduação da Faculdade de Direito da Universidade Estadual de Londrina - UEL. É autor de livros, advogado, consultor, parecerista e sócio titular do escritório Fujita Advocacia, com sede em São Paulo - SP (Brasil).
} 


\section{INTRODUÇÃO}

Nos últimos anos temos presenciado o surgimento de inovações tecnológicas surpreendentes, que têm causado revoluções nos modelos tradicionais de negócio, capazes de criarem novos mercados ou até mesmo de desestabilizar mercados até então sólidos e tradicionais.

Estas tecnologias disruptivas que geralmente são promovidas por empresas emergentes (startups), facilitam processos, barateiam produtos e serviços, democratizam o acesso aos bens e combatem o "não consumo", bem como o hiperconsumo, como foi o caso da Airbnb e da UBER, entre outras.

Por meio da Internet, do uso massivo de smartphones e de tecnologias Peer-to-Peer $(P 2 P)$ que permitem aproximar as pessoas, foi possível fomentar a economia chamada colaborativa ou economia compartilhada, a qual caiu no gosto da sociedade, fomenta o mercado e desafia legislações dos países.

A economia colaborativa ou economia compartilhada permite o consumo consciente e aumenta a eficiência do uso do bem, pois ao invés de comprá-lo, optamos pelo compartilhamento: paga-se pela locomoção, em vez da aquisição de um veículo que pode, no final das contas, ser subutilizado - e, em contrapartida, aquele que é proprietário do automóvel tem a possibilidade de auferir renda daquele que necessita do transporte eventual.

As aplicações tecnológicas têm promovido a economia compartilhada por facilmente permitir o encontro destas pessoas (peer-to-peer) que desejam ofertar seus produtos e serviços e daquelas que desejam consumi-los. Uma característica marcante deste tipo de economia é a eliminação parcial ou até total de intermediários nesta relação, uma vez que as pessoas transacionam diretamente umas com as outras por meio de plataformas digitais. Continuando o exemplo do transporte, ao invés de a pessoa dirigir-se até uma locadora de automóveis, ela pode firmar a transação diretamente com o condutor, através de um aplicativo. O mesmo ocorre ao alugar quartos ou apartamentos pela Airbnb, por exemplo: é possível realizar a locação diretamente com o proprietário do imóvel, ao invés de uma imobiliária ou hotel. 
Agentes econômicos até então "superpoderosos" se veem em situação de vulnerabilidade e instabilidade: a rede hoteleira se volta contra a Airbnb e a entidade de classe taxista se volta contra a Uber, principalmente alegando uma suposta concorrência desleal. Assim, está instalada a crise nos mercados.

No entanto, a economia colaborativa tem permitido um rendimento extra àquelas pessoas que necessitam complementar sua renda, ou até mesmo, ser a única fonte de renda diante da crise de desemprego que assola o país. Ademais, democratizou o acesso a bens e serviços que eram consumidos apenas por pessoas com maior poder aquisitivo, a exemplo do transporte por meio de táxis.

Com tantas inovações tecnológicas percebe-se um despreparo das autoridades e dos operadores do Direito, assim como, de certa forma, um vácuo legislativo que existiu até a promulgação da Lei ${ }^{\circ}$ 13.640, de 26 de março de 2018, que alterou a Lei ${ }^{\circ} 12.587 / 2012$, notando-se a dificuldade na adaptação do Direito ao fato social nesta seara da economia colaborativa, sendo certo que o Judiciário proferiu decisões contraditórias, o que causou grande insegurança jurídica. Muitas vezes, a primeira reação das autoridades foi proibir a operação destas plataformas tecnológicas, principalmente pela pressão de agentes econômicos tradicionais que até então dominavam o mercado.

O presente artigo tem como objetivo analisar as inovações tecnológicas baseadas na economia colaborativa/compartilhada, especialmente no âmbito do transporte individual privado de passageiros ofertado por meio de aplicativos, a insegurança jurídica instalada nestes novos modelos de negócio digitais e a necessidade ou não de legislação nesta seara.

O primeiro capítulo fará um breve estudo sobre o conceito de software, aplicativos (apps) e sua natureza jurídica; O segundo capítulo discorrerá sobre o fenômeno da economia colaborativa ou economia compartilhada. O terceiro capítulo analisará o caso concreto da UBER. O quarto capítulo tratará da necessidade ou não de legislação, com foco no caso concreto proposto. E finalmente, o quinto capítulo trará brevemente iniciativas legislativas no âmbito da economia colaborativa em geral, que culminaram com a regulamentação do modelo de negócio da UBER pela Lei nº 13.640/2018.

O estudo foi elaborado por meio de análise doutrinária e legislativa nacional, bem como estudo de caso sobre o tema proposto. 


\section{INOVAÇÕES TECNOLÓGICAS E SUA NATUREZA JURÍDICA}

Software é um conjunto de comandos escritos (instruções) em determinada linguagem de programação para serem interpretados por um hardware ${ }^{3}$ (computador, dispositivo móvel) com a finalidade de executar determinadas tarefas e funções de modo a alcançar o fim pelo qual foi desenvolvido. São conhecidos por programas (de computador) ou código-fonte. São exemplos de softwares, o Windows/Linux (sistema operacional), editores de texto (word, por exemplo), sites de comércio eletrônico, redes sociais, dentre outras aplicações.

O dicionário Michaelis o define como "qualquer programa ou grupo de programas que instrui o hardware sobre a maneira como ele deve executar uma tarefa, inclusive sistemas operacionais, processadores de texto e programas de aplicação."4

Os aplicativos, popularmente chamados de apps, são um tipo de software, porém com algumas características próprias. Um app é um software desenvolvido para ser instalado e utilizado em dispositivos móveis/portáteis, tais como, smartphones e tablets. Os aplicativos são disponibilizados em lojas virtuais de aplicativos, como por exemplo, a GooglePlay, a App Store, a BlackBerry World, entre outras. As caraterísticas que trazem vantagens no uso de um app em comparação com o software são: a facilidade e praticidade no seu uso, pela otimização da navegação e agilidade das ações; menor custo de acesso, porquanto o tráfego de dados é adaptado ao dispositivo em questão; exploração dos recursos do dispositivo móvel, tais como, GPS, câmera, dentre outros, e possibilidade de acesso off-line ao aplicativo, sem acesso à internet. ${ }^{5}$

Os apps, promovidos pelo uso massivo de smartphones, facilitaram pequenas e infinitas tarefas do nosso cotidiano, sem necessidade de estarmos em casa ou no trabalho diante de um computador. Não importa onde você esteja, se estiver portando seu smartphone com acesso à Internet é possível realizar pagamentos por meio do app de seu Banco, solicitar um táxi ou Uber, comprar seu almoço, reservar uma acomodação na Aibnb, por exemplo.

\footnotetext{
${ }^{3}$ Hardware é "a parte física do sistema de informatização. Trata-se de produto industrial e material ou corpóreo, que se distingue do software". (LISBOA, 2012, p. 494).

${ }^{4}$ MICHAELIS. Software. Disponível em: <http://michaelis.uol.com.br/moderno-portugues/busca/portuguesbrasileiro/software/>. Acesso em: 25 Nov.2017.

5 PORTO, Fabiano. Aplicativos mobile: definições, história e previsões. Disponível em: $<$ http://tectriadebrasil.com.br/blog/mercado-de-midias-sociais-blog/aplicativos-mobile-definicoes-historia-eprevisoes/>. Acesso em: 25 Nov.2017.
} 
Patrícia Peck Pinheiro (2016, p.375) faz uma distinção econômica relevante entre o software, propriamente dito, e o aplicativo:

\begin{abstract}
A recente indústria de aplicativos possui um modelo diferenciado, baseado no efeito "cauda longa", no qual, ao contrário da indústria de software que se desenvolveu cobrando um valor de licença considerável do cliente para uso do produto, oferta a gratuidade inicial para ter o retorno em pequenas doses durante a experiência do usuário que então adquire "elementos acessórios" para enriquecer o uso do produto.
\end{abstract}

Nosso ordenamento jurídico por meio da Lei de Propriedade Intelectual $\mathrm{n}^{\circ}$ 9.609/1998, que protege a propriedade intelectual de programa de computador, assim conceitua o software: "Programa de computador é a expressão de um conjunto organizado de instruções em linguagem natural ou codificada, contida em suporte físico de qualquer natureza, de emprego necessário em máquinas automáticas de tratamento da informação, dispositivos, instrumentos ou equipamentos periféricos, baseados em técnica digital ou análoga, para fazê-los funcionar de modo e para fins determinados."

Desta forma, o software pode ser classificado como um bem incorpóreo, ou seja, intangível ou abstrato. São bens que possuem valor econômico e existência jurídica.

Resta lembrar, que a Constituição Federal de 1988 previu, por meio da Emenda Constitucional $n^{\circ} 85$ de 2015, um capítulo inteiro com vistas à promoção e ao incentivo do desenvolvimento da ciência, tecnologia e inovação ${ }^{6}$.

\title{
2. A ECONOMIA COLABORATIVA OU ECONOMIA COMPARTILHADA
}

Estamos vivendo uma nova era do consumo e uma nova vertente da economia, com mudanças no papel dos agentes econômicos.

Do hiperconsumo ao consumo consciente, do acúmulo de bens à sustentabilidade. Se antigamente o consumo era concretizado pela relação entre fornecedores e consumidores (B2C, business-to-consumer), a economia compartilhada fomenta o consumo por meio de negociações entre as pessoas ( $\mathrm{P} 2 \mathrm{P}$, peer-to-peer), o que proporciona a redução dos custos dos bens, democratiza o acesso a eles, aumenta a concorrência e melhora a qualidade dos produtos e serviços. (MELLER-HANICH, 2016, p. 20).

A economia colaborativa privilegia o acesso eventual aos bens à aquisição de propriedade, por meio do compartilhamento. Afinal, se você mora no Centro da cidade e

\footnotetext{
${ }^{6}$ Constituição Federal. Artigos 218 ao 219-B.
} 
também trabalha no Centro, talvez não fosse razoável adquirir um veículo para uso eventual e mantê-lo a maior parte do tempo ocioso. Provavelmente, custar-lhe-ia muito mais caro do que optar por outros tipos de locomoção.

A economia colaborativa ou economia compartilhada ganhou notoriedade com a ampliação do acesso à Internet, com a massificação dos dispositivos eletrônicos portáteis conectados à rede (smartphones, entre outros) e pelas inovações tecnológicas em softwares em geral, principalmente pelos aplicativos (apps), na medida em que facilitou a aproximação das pessoas que possuem determinado bem às pessoas que necessitam do uso temporário deste bem, muitas vezes, com o uso por alguns minutos, horas ou dias.

Outrossim, a economia colaborativa ou economia compartilhada, segundo estudo técnico da Consultoria Legislativa da Câmara (SOUZA, 2016, p. 4):

refere-se a uma mesma ideia: maximização do uso ou exploração de um bem ou
recurso, de forma a aumentar os benefícios deles decorrentes, devido à diminuição
do período de ociosidade do bem ou recurso, possibilitada pela disseminação do uso
de dispositivos eletrônicos que permitem a conexão e interação de pessoas em
grandes redes de compartilhamento e pela disponibilização de avaliação de
qualidade pelos usuários dos bens ou recursos.

A precursora deste novo modelo de negócio foi a empresa emergente (startup) Zipcar, fundada em 1999 e formalmente lançada em 2000, por uma mulher inexperiente nos negócios, mas que sentiu a necessidade de ter acesso eventual a um veículo. A Zipcar permitia a locação agendada de carro por meio de plataforma digital: o cliente agendava o horário e o período de uso do carro; se dirigia ao estacionamento mais próximo para pegar o carro; usava e devolvia, sem necessidade de supervisão. A partir daí, novas empresas baseadas em economia compartilhada foram lançadas: a Wikipedia em 2000, a Facebook em 2004 e a Youtube em 2005. Uma década depois, surgiram a Airbnb, a Lyft e a Uber (CHASE, 2015, p.13-14), com investimentos bilionários (U\$450 milhões, U\$250 milhões e U\$3 bilhões, respectivamente).

O capitalismo está mudando, bem como a lógica de produção e consumo: antigamente, na era industrial, apenas quem possuía maior poder aquisitivo é quem poderia consumir e empreender, pois os recursos estavam concentrados nas mãos de poucos. Atualmente, com a Internet e as inovações tecnológicas especialmente baseadas na economia compartilhada, qualquer pessoa comum pode auferir renda com seus produtos e serviços, bem 
como consumi-los a custo mais baixo, compartilhando. É a cultura da colaboração e a falência dos monopólios (CHASE, 2015, p. XII).

\section{O CASO UBER: UMA EMPRESA DE SERVIÇO DE TRANSPORTE OU UMA EMPRESA DE INTERMEDIAÇÃO E TECNOLOGIA DA INFORMAÇÃO?}

A UBER chegou ao Brasil num momento de grande insatisfação da população em relação à qualidade e ao custo do transporte público, bem como na situação de "zona de conforto" na qual os taxistas operavam, principalmente por deter o monopólio do transporte público individual de passageiros. ${ }^{7}$

Um serviço inovador, uma plataforma digital completa e fácil de usar, caiu a UBER no gosto da sociedade. Se antes as pessoas ficavam à mercê dos taxistas, agora é possível optar pelo serviço, ser atendido em poucos minutos por um prestador, com um serviço de maior qualidade, com preço mais baixo e mais acessível a todos: bom para a população que passa a ter o poder de escolha e acesso ao serviço e bom para muitos desempregados que viram nesta plataforma tecnológica a solução de seus problemas financeiros.

No entanto, a classe taxista se viu vulnerável e ameaçada pela concorrência até então inexistente por deter o monopólio de transporte público individual remunerado de passageiros $^{8}$. Alegou concorrência desleal e não mediu forças para boicotar o seu concorrente, a Uber, inclusive, utilizando a força física para tal. Diversos condutores que prestavam serviços de transporte através do aplicativo da Uber foram atacados, sofrendo violências físicas e tendo seus carros destruídos. Uma verdadeira barbárie! Nada bom para a população, sequer para os trabalhadores que tentavam resgatar sua dignidade por meio do trabalho. Todavia, com a recente Lei $n^{\circ} 13.640$, de 26.03.2018, que alterou o inciso X, do art. $4^{\circ}$, da Lei $\mathrm{n}^{\mathrm{o}} 12.587 / 2012$, foi reconhecido o serviço de transporte viabilizado pela UBER como um transporte remunerado privado individual de passageiros: "serviço remunerado de transporte de passageiros, não aberto ao público, para a realização de viagens individualizadas ou

\footnotetext{
${ }^{7}$ LIMA, Simone Alvarez. A Constitucionalidade do Serviço da UBER à luz dos princípios da ordem econômica. Revista da Faculdade de Direito de São Bernardo do Campo. Disponível em: < https://revistas.direitosbc.br/index.php/fdsbc/search/authors/view?firstName=Simone\&middleName=Alvarez\&la stName=Lima\&affiliation=Universidade $\% 20$ Est $\%$ C $3 \%$ A1 cio\%20de\%20S\%C3\%A1\&country=> . Acesso em: 18 Nov.2017.

${ }^{8}$ A Lei $12.468 / 2011$ em seu artigo $2^{\circ}$ define como privativo o transporte público individual remunerado aos taxistas.
} 
compartilhadas solicitadas exclusivamente por usuários previamente cadastrados em aplicativos ou outras plataformas de comunicação em rede.”.

O aplicativo da UBER permite o cadastro do prestador de serviços de transporte e o cadastro das pessoas que necessitam deste serviço e aproxima ambos por meio do recurso de geolocalização $(G P S)$ para assim, localizar o prestador mais próximo do cliente naquele momento. Após a prestação do serviço de transporte, o pagamento é realizado pelo cliente também através do aplicativo, colocando-se a UBER como "agente limitado de cobrança desse prestador terceiro" ". Finda a execução do serviço, o cliente pode avaliar o serviço prestado pelo condutor, o que permite a construção da reputação deste prestador e colabora com a confiança no serviço. O aplicativo é tipicamente baseado na economia compartilhada.

Assim, o modelo de negócio e o papel dos agentes econômicos foram modificados: agora já não há mais apenas a figura da empresa prestadora de serviços e o consumidor $(B 2 C$, business-to-consumer), mas sim um negócio entre pessoas ( $P 2 P$, peer-to-peer) viabilizado por um aplicativo, cujo detentor é uma empresa (MELLER-HANICH, 2016, p. 20). Não há mais o intermediário "Rádio Taxi" para ofertar o serviço e a empresa de aplicativo não é detentora dos carros utilizados na prestação do serviço e sim, o próprio prestador do serviço. Mas afinal, qual é a natureza jurídica desta empresa? Uma empresa de transportes ou uma empresa de intermediação e tecnologia?

Esta dúvida pairou por muito tempo na sociedade em geral e na comunidade jurídica, causando grande insegurança jurídica proveniente de decisões judiciais divergentes proferidas acerca da proibição ou não da operação do serviço. Portanto, é importante analisarmos os agentes econômicos envolvidos, a natureza jurídica deste tipo de empresa e a relação jurídica estabelecida entre os agentes.

\section{a) A Empresa UBER}

A empresa UBER é regularmente constituída no Brasil. De acordo com a Receita Federal, a UBER está inscrita pelo nome empresarial "UBER DO BRASIL TECNOLOGIA LTDA.”, natureza jurídica sob o código "206-2 - Sociedade Empresária Limitada”, com

\footnotetext{
${ }^{9}$ Consta nos termos de uso da UBER: "Após você ter recebido serviços ou bens obtidos por meio do uso do Serviço, a Uber facilitará o pagamento do respectivo Preço em nome do Prestador Terceiro na qualidade de agente limitado de cobrança desse Prestador Terceiro. O pagamento do Preço feito dessa maneira será considerado pagamento feito diretamente por você ao Prestador Terceiro.”
} 
atividade econômica sob o código "74.90-1-04 - Atividades de intermediação e agenciamento de serviços e negócios em geral, exceto imobiliários". ${ }^{10}$

Suas atividades econômicas secundárias, ainda conforme registro na Receita Federal, se direcionam ao desenvolvimento de software: "62.02-3-00 - Desenvolvimento e licenciamento de programas de computador customizáveis; 62.09-1-00 - Suporte técnico, manutenção e outros serviços em tecnologia da informação; 70.20-4-00 - Atividades de consultoria em gestão empresarial, exceto consultoria técnica específica; 73.19-0-04 Consultoria em publicidade; 63.19-4-00 - Portais, provedores de conteúdo e outros serviços de informação na internet”.

Como demonstrado, a empresa está inscrita na atividade de intermediação de serviços e negócios, com atividades econômicas de desenvolvimento de software, preponderantemente, não sendo uma empresa de transporte de passageiro. Importante recordar que a empresa não tem qualquer carro ou frota em seu modelo de negócio, apenas aproxima a pessoa que necessita de transporte à pessoa que presta o serviço de transporte, até então não regulamentado por lei. ${ }^{11}$ A título de curiosidade, diferentemente da UBER, a empresa COOPERTAX, empresa de rádio taxi em operação desde 1981, está classificada na Receita Federal com código de atividade econômica principal "49.23-0-01 - Serviço de táxi” e natureza jurídica "214-3 - Cooperativa"12.

A empresa UBER classifica os condutores cadastrados na plataforma como "Prestadores Terceiros" e os usuários do serviço como, simplesmente, "Usuários" nos Termos de Uso de sua plataforma digital. Ainda, em sua cláusula "2. Os Serviços", a empresa descreve que os serviços integram uma plataforma de tecnologia e, em letras "garrafais", afirma que o usuário reconhece que a UBER não é uma empresa de transporte e que o serviço é prestado por prestadores independentes que não são funcionários da UBER. ${ }^{13}$

\footnotetext{
${ }^{10}$ RECEITA FEDERAL. Emissão de Comprovante de Inscrição e de Situação Cadastral. Disponível em: < http://www.receita.fazenda.gov.br/PessoaJuridica/CNPJ/cnpjreva/Cnpjreva_Solicitacao.asp>. Acesso em: 25 Nov.2017.

${ }^{11}$ A Lei de Mobilidade Urbana não previa o transporte remunerado privado individual de passageiros. A Lei ${ }^{\circ}$ 13.640, de 28.03.2018, passou a regulamentá-lo.

${ }^{12}$ RECEITA FEDERAL. Emissão de Comprovante de Inscrição e de Situação Cadastral. Disponível em: < http://www.receita.fazenda.gov.br/PessoaJuridica/CNPJ/cnpjreva/Cnpjreva_Solicitacao.asp>. Acesso em: 25 Nov.2017.

${ }^{13}$ UBER. Termos e Condições. Disponível em: <https://www.uber.com/pt-BR/legal/terms/br/>. Acesso em: 25 Nov.2017.
} 
Ademais, a empresa está sujeita à carga tributária inerente a sua classificação, qual seja, tributos federais (como PIS, Confins e Imposto de Renda), quanto municipais (como ISS e contribuições municipais). ${ }^{14}$

b) Prestadores Terceiros

Os condutores que prestam serviços por meio da plataforma tecnológica da UBER devem primeiramente ser cadastrados na plataforma e devem seguir alguns critérios estabelecidos pela empresa, tais como, $\mathrm{CNH}$ permanente de atividade remunerada, CRLV do veículo e padrão mínimo de veículo conforme a categoria de prestação de serviços (UberX, UberBlack, por exemplo). ${ }^{15}$

Os prestadores de serviço de transporte cadastrados no aplicativo UBER são classificados como "Prestadores Terceiros", não são funcionários da empresa, não tem horário mínimo ou fixo para cumprir e prestam o serviço com o seu próprio veículo ou de terceiros. Podem ser considerados como trabalhadores autônomos, prestam serviço de transporte de passageiros, sujeitos aos tributos inerentes a esta classificação, assim como tributos relacionados à aquisição e mantença do veículo (LEAL e TANCREDO, 2016, p. 158-175).

c) Usuário

Os usuários são aqueles que solicitam o serviço de transporte por meio da plataforma tecnológica da UBER. Devem primeiramente ser cadastrados na plataforma e aceitar os termos de uso, concordando com as cláusulas ali descritas, referentes ao serviço, ao preço, ao pagamento, às obrigações, responsabilidades e política de privacidade, entre outros. ${ }^{16}$

Importante mencionar que os pagamentos dos tributos relacionados ao serviço prestado são de responsabilidade do usuário, que reembolsa o Prestador Terceiro e/ou a Uber

\footnotetext{
${ }^{14}$ PROCHNO, Pedro. Em 2017, Uber já pagou mais de R\$ 495 milhões em impostos no Brasil. Disponível em: <https://www.uber.com/pt-BR/newsroom/em-2017-uber-pagou-mais-de-r-495-milhoes-em-impostos-nobrasil/>. Acesso em: 25 Nov.2017.

${ }^{15}$ UBER. Comece a dirigir com a Uber. Disponível em: <https://www.uber.com/pt-BR/drive/>. Acesso em: 25 Nov.2017.

${ }^{16}$ UBER. Termos e Condições. Disponível em: <https://www.uber.com/pt-BR/legal/terms/br/>. Acesso em: 25 Nov.2017.
} 
por todas as tarifas, taxas, impostos e/ou contribuições governamentais, conforme estipula os termos de uso do aplicativo. ${ }^{17}$

\section{REGULAMENTAÇÃO DO TRANSPORTE REMUNERADO PRIVADO INDIVIDUAL DE PASSAGEIROS POR MEIO DE APLICATIVOS NO BRASIL}

a) Da Constitucionalidade e Legalidade do Serviço

Inicialmente é importante recordarmos um importante princípio constitucional da legalidade no qual estipula que "ninguém será obrigado a fazer ou deixar de fazer alguma coisa senão em virtude de lei" (CF, art. 5', II), que significa "lei existente no momento em que o fazer ou deixar de fazer está acontecendo" (SILVA, 2015, p. 433). Pois bem.

Na seara do transporte individual de passageiros a regulamentação existente dispõe sobre a competência administrativa e a competência legislativa para regular o tema. $\mathrm{O}$ artigo 21, XII, "e", da CF/1988 destaca que compete à União explorar diretamente ou por meio de autorização, concessão ou permissão o serviço de transporte rodoviário interestadual e internacional de passageiros. No mesmo artigo, o inciso XX prevê a competência administrativa da União instituir as diretrizes de desenvolvimento urbano, inclusive, dos transportes (DUQUE, 2016, p. 505-506).

Na sequência, o artigo 22, XI da CF/1988 estabelece que compete igualmente à União, de forma privativa, legislar sobre o tema trânsito e transporte. E mais adiante, a Constituição estipula a competência dos Municípios para legislar sobre assunto local (CF, art. $30, \mathrm{I})$.

Duas legislações federais tratam do tema: Lei 12.468/2011, que regulamenta a profissão do taxista e a Lei 12.587/2012, que institui as diretrizes da Política Nacional de Mobilidade Urbana. Assim, vejamos.

O artigo $2^{\circ}$ da Lei 12.468/2011 estipula que é atividade privativa dos taxistas o transporte público individual remunerado de passageiros e no artigo $3^{\circ}$, impõe diversos requisitos para tal. Já a Lei 12.587/2012, em seu inciso VIII, do artigo $4^{\circ}$, define o transporte público individual como sendo um "serviço remunerado de transporte de passageiros aberto

\footnotetext{
${ }^{17}$ UBER. Termos e Condições. Disponível em: <https://www.uber.com/pt-BR/legal/terms/br/>. Acesso em: 25 Nov.2017. 
ao público, por intermédio de veículos de aluguel, para a realização de viagens individualizadas;”. A Constituição Federal nada definiu quanto à natureza jurídica do táxi, mas na maioria dos municípios, o entendimento é de que se trata de serviço de utilidade pública, dependendo somente de autorização do Poder Público para operar (DUQUE, 2016, p.511-512).

O inciso VII do mesmo artigo $4^{\circ}$ da Lei $12.587 / 2012$ caracteriza o transporte privado coletivo como sendo o "serviço de transporte de passageiros não aberto ao público para a realização de viagens com características operacionais exclusivas para cada linha e demanda". Este seria o caso dos fretados, por exemplo.

A UBER, empresa privada no ramo de intermediação e tecnologia, viabiliza a prestação de serviço de transporte privado individual, não essencial e não aberto ao público, uma vez que atende somente às pessoas que se cadastram no aplicativo. Assim, os condutores prestadores de transporte privado individual cadastrados na plataforma da UBER não se confundem com taxistas e exercem seu trabalho de acordo com os ditames do artigo $5^{\circ}$, XIII da $\mathrm{CF} / 1988$, o qual estabelece que "é livre o exercício de qualquer trabalho, ofício ou profissão, atendidas as qualificações profissionais que a lei estabelecer.”.

Resta ressaltar que a República Federativa do Brasil tem como fundamentos a dignidade da pessoa humana, os valores sociais do trabalho e da livre iniciativa $\left(\mathrm{CF}\right.$, art. $1^{\circ}$, III e IV) e tem como objetivos fundamentais uma sociedade livre, justa e solidária, o desenvolvimento social e a erradicação da pobreza (CF, art. $3^{\circ}$, I, II e III).

Dedicou-se, em capítulo próprio, à defesa da ordem econômica fundada na valorização do trabalho humano e na livre iniciativa, com vistas à justiça social, tendo como princípios a livre concorrência, a defesa do consumidor e a busca do pleno emprego $(\mathrm{CF}$, art. 170), assegurando, em tempo, o livre exercício de qualquer atividade econômica, independentemente de autorização do poder público $^{18}$. Significa dizer que tais princípios permitem o livre exercício de atividade econômica do empreendedor de inovar e promover produtos e serviços que não sejam ilegais, que gerem oportunidades de trabalho, que

\footnotetext{
${ }^{18} \mathrm{CF} / 1988$. Art. 170. Parágrafo único. É assegurado a todos o livre exercício de qualquer atividade econômica, independentemente de autorização de órgãos públicos, salvo nos casos previstos em lei.
} 
fomentem a concorrência e que permitam a livre escolha do consumidor, o que colabora com a dignidade da pessoa humana (DUQUE, 2016, p. 512-517).

b) Do Projeto de Lei para a Regulamentação do Serviço

Conforme verificado alhures, o serviço via app da UBER não é ilegal e muito menos inconstitucional, no entanto havia um vácuo legislativo principalmente com relação ao conceito de transporte individual privado de passageiros. Assim, por que seria então necessária uma regulamentação?

A resposta desta pergunta é baseada na sociologia jurídica. $\mathrm{O}$ direito é o produto do poder social, dos valores sociais e dos fatores históricos, econômicos, culturais, morais, religiosos, entre outros. O direito vem para impor regras de convívio social e assim manter a ordem, pois "o controle social é uma condição básica da vida social” (SIQUEIRA JR., 2012, p. 233).

Paulo Hamilton Siqueira Jr. (2012, p. 231) explica:

\begin{abstract}
Se, de um lado, o direito é o resultado de múltiplos fatores sociais, de outro, é o instrumento mais qualificado de controle e transformação social, porque detentor do poder de coação. Nessa qualidade, as normas atuam poderosamente sobre a conduta dos membros da sociedade. E, nesse sentido, o direito é também produtor de condutas sociais.
\end{abstract}

Muitas vezes o ordenamento jurídico não está preparado para absorver uma nova realidade trazida por uma inovação tecnológica, o que pode causar instabilidades e insegurança jurídica nas relações sociais. Quando se trata de impactos em instituições tradicionais e agentes econômicos que até então dominavam o mercado, as relações humanas podem gerar um verdadeiro caos até que o Estado venha a manifestar-se sobre o fato social e pacifique os conflitos por meio de leis, por exemplo.

O caso da UBER, inovação tecnológica voltada à economia colaborativa ou compartilhada na qual, ao mesmo tempo que possibilitou um serviço mais barato e uma forma de trabalho àqueles que necessitam, causou uma verdadeira guerra entre taxistas, condutores do aplicativo, a empresa UBER, bem como entre os políticos e os consumidores em geral. A falta de clareza ou previsão legislativa gerava polêmica e atos violentos nas relações sociais.

Com vistas à harmonização dos serviços dos taxistas e dos condutores de transporte privado individual de passageiros, a Câmara dos Deputados propôs em abril de 2017 o Projeto 
de Lei $n^{\circ} 28 / 2017$, o qual alterava a Lei 12.587/2012 para regulamentar o transporte remunerado privado individual de passageiros ${ }^{19}$. Em consulta pública sobre o texto do projeto de lei, 44.861 pessoas votaram a favor do texto e 262.121 votaram contra $^{20}$.

Em síntese, o projeto de lei, em sua redação original, previa:

i. A definição de transporte remunerado privado individual de passageiros como aquele "não aberto ao público, por meio de veículos de aluguel, para a realização de viagens individualizadas ou compartilhadas solicitadas exclusivamente por usuários previamente cadastrados em aplicativos ou outras plataformas de comunicação em rede" (Lei 12.587/2012, art. $\left.4^{\circ}, \mathrm{X}\right)$.

Note que a redação original previa, estranhamente, apenas o transporte por meio de veículos de aluguel.

ii. Inclusão do artigo 11-A para definir a competência exclusiva dos Municípios e Distrito Federal para regulamentar e fiscalizar o serviço, prevendo a cobrança de tributos municipais; a exigência de contratação de seguro de acidentes pessoais a passageiros (APP), $\operatorname{DPVAT}^{21}$ e a exigência de inscrição do motorista no INSS ${ }^{22}$.

iii. Inclusão do artigo 11-B para estabelecer condições ao condutor para a prestação do serviço de transporte, tais como, a necessidade de carteira nacional de habilitação na categoria $B$ ou superior; conduzir veículo que atenda às condições de idade máxima e às características definidas pelas autoridades; possuir e portar autorização emitida pelo Município ou Distrito Federal no local da prestação do serviço; emitir e manter o $\mathrm{CRLV}^{23}$ “obrigatoriamente em seu nome, como proprietário, fiduciante ou arrendatário, com registro e emplacamento do veículo na categoria aluguel.”.

iv. Caracterização de transporte ilegal de passageiros em caso de descumprimento da lei (Lei 12.587/2012, art. 11-B, parágrafo único).

19 SENADO. Projeto de Lei da Câmara $\mathbf{n}^{\mathbf{0}}$ 28, de 2017. Disponível em: <http://www25.senado.leg.br/web/atividade/materias/-/materia/128659>. Acesso em: 25 Nov.2017.

20 SENADO. 28/2017. PLC Disponível em:

<https://www12.senado.leg.br/ecidadania/visualizacaomateria?id=128659>. Acesso em: 25 Nov.2017.

${ }^{21}$ Seguro obrigatório de danos pessoais causados por veículos automotores de vias terrestres

${ }^{22}$ Instituto Nacional do Seguro Social

${ }^{23}$ Registro e Licenciamento de Veículo 
Claramente é possível verificar que a Câmara elaborou e aprovou projeto de lei prótaxista com posição intervencionista na atividade privada, de modo a beneficiar a categoria dos taxistas, estabelecendo a necessidade de autorização para o condutor do aplicativo (placa vermelha) e a exigência de que o condutor seja proprietário do veículo.

Posteriormente, em 31/10/2017, o Projeto de Lei no 28/2017 da Câmara foi aprovado pelo Senado com emendas, totalizando 46 votos a favor e uma abstenção ${ }^{24}$. O Senado propôs as seguintes alterações no Projeto de Lei:

i. Removeu da definição de transporte remunerado privado individual de passageiro o texto "veículo de aluguel”. (Lei 12.587/2012, art. 4, X).

ii. Restringiu a competência dos Municípios apenas para a fiscalização do serviço.

iii. No artigo 11-B, removeu a restrição de CRLV “obrigatoriamente em seu nome, como proprietário, fiduciante ou arrendatário, com registro e emplacamento do veículo na categoria aluguel.”, bastando apenas emitir e manter o CRLV. Ademais, incluiu a necessidade da apresentação de certidão negativa de antecedentes criminais.

O Senado adotou uma posição mais liberal pró-desenvolvimento econômico e iniciativa privada, retirando a necessidade de autorização para o condutor do aplicativo (placa vermelha) e a exigência de que o condutor seja proprietário do veículo. No entanto, para garantir a segurança dos usuários, propôs a apresentação de certidão negativa de antecedentes criminais dos prestadores do serviço.

O Projeto de Lei $n^{\circ}$ 28/2017 retornou para análise da Câmara e foi aprovado em 28/02/2018, no entanto foi mantido o texto original que previa a competência dos municípios para regulamentação e fiscalização da atividade ${ }^{25}$. O texto final se encontra na Lei $n^{\circ} 13.640$, de 26 de março de 2018, que alterou a Lei no $12.587 / 2012$.

\footnotetext{
${ }^{24}$ SENADO. Projeto de regulamentação do Uber é alterado e volta para a Câmara. Disponível em: $<$ https://www12.senado.leg.br/noticias/materias/2017/10/31/projeto-de-regulamentacao-do-uber-e-alterado-evolta-para-a-camara>. Acesso em: 25 Nov.2017.

${ }^{25}$ ÉPOCA NEGÓCIOS. Câmara aprova projeto que beneficia empresas de aplicativo como Uber e Cabify. Disponível em: <https://epocanegocios.globo.com/Brasil/noticia/2018/03/camara-aprova-projeto-que-beneficiaempresas-de-aplicativo-como-uber-e-cabify.html>. Acesso em: 28 Mar.2018.
} 


\section{INICIATIVAS LEGISLATIVAS PARA A REGULAMENTAÇÃO DA ECONOMIA COLABORATIVA NO BRASIL}

a) Comissão Especial do Marco Regulatório da Economia Colaborativa ${ }^{26}$

Instalada em agosto/2017 com a presidência do deputado federal Herculano Passos (PSD/SP) e com relatoria do deputado Thiago Peixoto (PSD/GO), a Comissão Especial do Marco Regulatório da Economia Colaborativa teve o objetivo de propor possíveis legislações para regulamentar o mercado estabelecido em plataformas digitais baseadas em economia colaborativa, de modo a reduzir a insegurança jurídica dos empreendedores, daqueles que ofertam o bem ou serviço e daqueles que o consomem no Brasil.

A Comissão foi formada para agregar esforços de estudo sobre o tema, unindo convidados especialistas, acadêmicos, autoridades, representantes da sociedade, bem como audiências públicas para debater a economia colaborativa nos seguintes setores: turismo, mobilidade urbana, entretenimento, aluguel e permuta de bens móveis, financiamento coletivo (crowdfunding), fintech, varejo colaborativo, alimentação, fluxo de mídia (streaming), educação, pesquisa de preços e business analytics, compartilhamento de imóveis e espaços e ambiente para surgimento de startups.

b) Projeto de Lei $n^{\circ} 7579 / 2017^{27}$

O Projeto de Lei $n^{\circ} 7.579 / 2017$, de autoria do deputado Lucas Vergílio (SD/GO) apresentado em maio/2017, previa a regulação da atividade econômica realizada por meio de plataformas digitais que intermediassem prestações de serviços entre usuários previamente cadastrados, a disponibilização de bens à locação ou compartilhamento de recursos, apenas em plataformas que aceitassem usuários pessoa física como demandante e ofertante e que cobrassem taxas dos usuários por utilização da plataforma.

c) Lei $\mathrm{n}^{\mathrm{o}}$ 13.640, de 26.03.2018

Com todos os embates e problemas enfrentados, a UBER, como serviço de transporte remunerado privado individual de passageiros, não aberto ao público, para a realização de

${ }^{26}$ CÂMARA DOS DEPUTAdOS. Marco Regulatório da Economia Colaborativa. Disponível em: $<\mathrm{http} / / / \mathrm{www} 2 . c a m a r a . l e g . b r / a t i v i d a d e-l e g i s l a t i v a / c o m i s s o e s / c o m i s s o e s-t e m p o r a r i a s / e s p e c i a i s / 55 a-$

legislatura/cesp-marco-regulatorio-da-economia-colaborativa〉. Acesso em: 25 Nov.2017.

27 CÂMARA DOS DEPUTADOS. PL 7579/2017. Disponível em: <http://www.camara.gov.br/proposicoesWeb/fichadetramitacao?idProposicao=2136364>. Acesso em: 25 Nov.2017. 
viagens individualizadas ou compartilhadas solicitadas exclusivamente por usuários previamente cadastrados em aplicativos ou outras plataformas de comunicação em rede, veio a ser, finalmente, regulamentado pela Lei $\mathrm{n}^{\circ} 13.640$, de 26.03.2018, que alterou a redação da Lei ${ }^{\circ} 12.587 / 2012$.

Atribuiu a lei aos municípios e ao Distrito Federal a regulamentação e a fiscalização do serviço de transporte remunerado privado individual de passageiros, cabendo-lhes a observância das seguintes diretrizes: a) a efetiva cobrança dos tributos municipais devidos pela prestação de serviço; b) a exigência de contratação de seguro de Acidentes Pessoais e Passageiros (APP) e do Seguro Obrigatório de Danos Pessoais causados por Veículos Automotores de Vias Terrestres (DPVAT); c) exigência de inscrição do motorista como contribuinte individual do Instituto Nacional do Seguro Social. Ademais, exige a lei que o condutor possua Carteira Nacional de Habilitação na categoria B ou superior que contenha a informação de que exerce atividade remunerada; que conduza veículo que atenda aos requisitos de idade máxima e às características exigidas pela autoridade de trânsito e pelo poder público municipal e do Distrito Federal; que mantenha o Certificado de Registro e Licenciamento de Veículo (CRLV); e apresente a certidão negativa de antecedentes criminais. 


\section{CONCLUSÃO}

Conforme foi visto, estamos vivendo a era dos aplicativos, de inovações tecnológicas que aproximam cada vez mais as pessoas e rompem com modelos de negócios tradicionais que até então dominavam o mercado. São as tecnologias baseadas em economia compartilhada ou colaborativa.

Estas inovações, especialmente o caso analisado da plataforma tecnológica da UBER na seara do transporte individual privado de passageiros, causou revolta por parte da classe taxista que alegava e alega a ilegalidade do serviço e a concorrência desleal, ao passo que a iniciativa privada justifica estar em seu direito à livre iniciativa. $\mathrm{O}$ vácuo legislativo na definição e regulamentação do transporte individual privado de passageiros gerou polêmica e atos de violência na sociedade.

A empresa UBER não é uma empresa de transportes, inscrita na atividade de intermediação de serviços e negócios, com atividades econômicas de desenvolvimento de software. A empresa não possui qualquer carro ou frota em seu modelo de negócio, não possui funcionários prestadores do serviço de transporte e apenas aproxima a pessoa que necessita de transporte à pessoa que presta o serviço.

Conforme foi visto, o serviço de transporte privado individual ofertado por meio de aplicativo, tal qual a UBER, não é inconstitucional e ilegal. O transporte individual privado de passageiros que não estava previsto na Lei de Mobilidade Urbana, agora se encontra devidamente regulamentado.

Venceram a livre iniciativa e a livre concorrência protegidas pela Constituição, o que significa dizer que o empresário tem a liberdade em suas iniciativas econômicas, desde que com vistas à justiça social, à existência digna, à defesa do consumidor e a busca do pleno emprego, entre outros. A inovação tecnológica tem proporcionado uma nova forma de trabalho e renda, a livre escolha do serviço pelo consumidor e tem colaborado com a dignidade da pessoa humana.

Apesar da constitucionalidade e da legalidade do serviço, a regulamentação mostrouse indispensável, como uma forma de garantia da segurança jurídica e da pacificação social. $\mathrm{O}$ direito deve acompanhar a evolução da sociedade e garantir a ordem social. 
O Projeto de Lei $n^{\circ}$ 28/2017 proposto pela Câmara claramente adotou posição intervencionista na atividade privada e em prol da classe taxista ao criar a necessidade de autorização do poder público para o condutor, dentre outras exigências. O Senado emendou, retirando tal obrigação, colocando-se numa posição mais liberal e em prol do desenvolvimento e da economia. Reconsiderando a opinião da sociedade, a Câmara aprovou o projeto com as emendas do Senado, no entanto manteve a competência dos municípios para regulamentação e fiscalização da atividade. Foi um meio termo. E assim foi promulgada a Lei 13.640, em 26 de março de 2018, que já se encontra em vigor.

\section{REFERÊNCIAS}

BRASIL. Constituição (1988). Constituição da República Federativa do Brasil. Disponível em: <http://www.planalto.gov.br/ccivil_03/constituicao/ConstituicaoCompilado.htm>. Acesso em: 18 Nov.2017.

Institui as diretrizes da Política Nacional de Mobilidade Urbana. Lei 12.587, de 3 de janeiro de 2012. Brasília, 2012. Disponível em: < http://www.planalto.gov.br/ccivil_03/_ato2011-2014/2012/lei/112587.htm>. Acesso em: 18 Nov.2017.

Propriedade Industrial. Lei $\mathrm{n}^{\circ}$. 9.279/96, de 14 de maio de 1996. Regula direitos e obrigações relativos à propriedade industrial. Brasília, 1996. Disponível em: <http://www.planalto.gov.br/ccivil_03/leis/L9279.htm>. Acesso em: 18 Nov.2017.

Regulamenta a profissão de taxista. Lei 12.468, de 26 de agosto de 2011.

Brasília, 2011. Disponível em: < http://www.planalto.gov.br/ccivil_03/_ato20112014/2012/lei/112587.htm>. Acesso em: 18 Nov.2017.

\section{CÂMARA DOS DEPUTADOS. Marco Regulatório da Economia Colaborativa.}

Disponível em: <http://www2.camara.leg.br/atividade-legislativa/comissoes/comissoestemporarias/especiais/55a-legislatura/cesp-marco-regulatorio-da-economia-colaborativa>. Acesso em: 25 Nov.2017.

CÂMARA DOS DEPUTADOS. PL 7579/2017. Disponível em: <http://www.camara.gov.br/proposicoesWeb/fichadetramitacao?idProposicao=2136364>. Acesso em: 25 Nov.2017. 
CHASE, Robin. Economia Compartilhada: Como pessoas e plataformas da Peers Inc. estão reinventando o capitalismo; tradução de Cristina Yamagami. - São Paulo: HSM do Brasil, 2015.

DUQUE, Marcelo Schenk. A Constitucionalidade do Serviço UBER no Brasil. Revista Direito do Consumidor. vol. 105. ano 25. p.501-522. São Paulo: Ed. RT, maio-jun.2016. ÉPOCA NEGÓCIOS. Câmara aprova projeto que beneficia empresas de aplicativo como Uber Cabify. Disponível em: <https://epocanegocios.globo.com/Brasil/noticia/2018/03/camara-aprova-projeto-quebeneficia-empresas-de-aplicativo-como-uber-e-cabify.html>. Acesso em: 28 Mar.2018 LEAL, Bruno Bianco; Tancredo, Thiago Mafra. Uber e Direito Tributária: Uma análise tributária desta nova tecnologia. XXV Encontro Nacional do CONPEDI - Brasília/DF. Disponível em:

https://www.conpedi.org.br/publicacoes/y0ii48h0/1vtu3xbu/x3FllNp179UFA6es.pdf>. Acesso em: 18 Nov.2017.

LIMA, Simone Alvarez. A Constitucionalidade do Serviço da UBER à luz dos princípios da ordem econômica. Revista da Faculdade de Direito de São Bernardo do Campo. Disponível em:

https://revistas.direitosbc.br/index.php/fdsbc/search/authors/view?firstName=Simone\&middle Name $=$ Alvarez\&lastName $=$ Lima\&affiliation=Universidade $\% 20$ Est $\%$ C3\%A1 cio $\% 20 \mathrm{de} \% 20 \mathrm{~S}$ \%C3\%A1\&country=>. Acesso em: 18 Nov.2017.

LISBOA, Roberto Senise. Manual de Direito Civil: Direitos Reais e Direitos Intelectuais. 6.ed. São Paulo: Saraiva, 2012.

MELLER-HANICH, Caroline. Economia compartilhada e proteção do consumidor. Trad. Ardyllis Soares. Revista Direito do Consumidor. vol. 105. ano 25. p.19-31. São Paulo: Ed. RT, maio-jun.2016.

MICHAELIS. Software. Disponível em: <http://michaelis.uol.com.br/modernoportugues/busca/portugues-brasileiro/software/>. Acesso em: 25 Nov.2017.

PINHEIRO, Patrícia Peck. Direito digital. 6. ed. São Paulo: Saraiva, 2016.

PORTO, Fabiano. Aplicativos mobile: definições, história e previsões. Disponível em: $<$ http://tectriadebrasil.com.br/blog/mercado-de-midias-sociais-blog/aplicativos-mobiledefinicoes-historia-e-previsoes/>. Acesso em: 25 Nov.2017. 
PROCHNO, Pedro. Em 2017, Uber já pagou mais de R\$ 495 milhões em impostos no

Brasil. Disponível em: <https://www.uber.com/pt-BR/newsroom/em-2017-uber-pagou-maisde-r-495-milhoes-em-impostos-no-brasil/>. Acesso em: 25 Nov.2017.

RECEITA FEDERAL. Emissão de Comprovante de Inscrição e de Situação Cadastral.

Disponível em:

http://www.receita.fazenda.gov.br/PessoaJuridica/CNPJ/cnpjreva/Cnpjreva_Solicitacao.asp>. Acesso em: 25 Nov.2017.

SENADO. Projeto de Lei da Câmara $\mathbf{n}^{\mathbf{0}}$ 28, de 2017. Disponível em: <http://www25.senado.leg.br/web/atividade/materias/-/materia/128659>. Acesso em: 25 Nov.2017.

SENADO. PLC 28/2017. Disponível em: <https://www12.senado.leg.br/ecidadania/visualizacaomateria?id=128659>. Acesso em: 25 Nov.2017.

SENADO. Projeto de regulamentação do Uber é alterado e volta para a Câmara. Disponível em: <https://www12.senado.leg.br/noticias/materias/2017/10/31/projeto-deregulamentacao-do-uber-e-alterado-e-volta-para-a-camara> Acesso em: 25 Nov.2017.

SILVA, José Afonso da. Curso de Direito Constitucional Positivo, 38. ed. Brasil: PC Editorial Ltda, 2015.

SIQUEIRA JR., Paulo Hamilton. Teoria do Direito. 3.ed. São Paulo: Saraiva, 2012.

SOUZA, Iuri Gregório de. Economia Colaborativa - Estudo Técnico ago/2016. Disponível em: < http://www2.camara.leg.br/a-camara/documentos-e-pesquisa/estudos-e-notastecnicas/areas-da-conle/tema10/2016_13983_economia-colaborativa_iuri-gregorio-de-souza>. Acesso em: 18 Nov.2017.

UBER. Comece a dirigir com a Uber. Disponível em: 〈https://www.uber.com/pt-BR/drive/> . Acesso em: 25 Nov.2017.

UBER. Termos e Condições. Disponível em: <https://www.uber.com/ptBR/legal/terms/br/>. Acesso em: 25 Nov.2017. 